\title{
A Numerical Classification of Fission Yeasts of the Genus Schizosaccharomyces Lindner
}

\author{
By PAUL D. BRIDGE*† AND JOHN W. MAY \\ Department of Microbiology, Monash University, Clayton, Victoria 3168, Australia
}

(Received 10 January 1984; revised 26 March 1984)

A numerical classification of the yeast genus Schizosaccharomyces was undertaken using 60 strains and 100 characters. Three distinct clusters were observed, corresponding to $S$. pombe $\left(S_{S M}=83 \%\right)$, both varieties of $S$. japonicus $\left(S_{S M}=78 \%\right)$, and $S$. octosporus $\left(S_{S M}=75 \%\right)$. Schizosaccharomyces malidevorans and $S$. slooffiae, each of which is available only as the type, could not be differentiated from $S$. pombe and $S$. octosporus respectively.

\section{INTRODUCTION}

The yeast genus Schizosaccharomyces was first described by Lindner from samples of Bantu beer (Slooff, 1970). All members of the genus undergo binary fission during vegetative reproduction, a characteristic unique among ascosporogenous yeasts (Lodder, 1970; Barnett et al., 1979). The history of the genus is well described by Slooff (1970) who listed four species including two varieties: $S$. japonicus var. japonicus, $S$. japonicus var. versatilis, $S$. malidevorans, $S$. octosporus and $S$. pombe, the last being the type species. Subsequently, a fifth species, $S$. slooffiae, was described by Kumbhojkar (1972); however, more recently, $S$. malidevorans was re-proposed as a variety of $S$. pombe on the basis of interfertility (Sipiczki et al., 1982).

During the last three decades, the major influence in yeast classification has been The Yeasts a Taxonomic Study (Lodder \& Kreger-van Rij, 1952; Lodder, 1970). In contrast to the hierarchical approach employed in the foregoing work, the assessment of overall similarity on the basis of equal weighting of characters combined with the use of numerical processing procedures has also been employed with several genera of yeasts (Campbell, 1972, 1973, 1975; Kockova-Kratochvilova et al., 1978). For such an assessment to be valid, at least 50 characters should be used in the comparisons (Sneath, 1978); however, of the 78 characters iisted for yeasts by Barnett et al. (1979), only 15 were differential for fission yeasts. In this paper we describe a set of traditional and novel characters which we have used to construct a numerical classification of the genus Schizosaccharomyces.

\section{METHODS}

Media. The basic media were: MEA - Malt Extract Agar (Oxoid); PYGM - peptone, yeast extract, glucose medium (Conti \& Naylor, 1959), EMM2A - Edinburgh minimal medium no. 2 (Mitchison, 1970) supplemented with adenine (50 $\left.\mathrm{mg} \mathrm{1}^{-1}\right)$; EMM2A(G-3) - EMM2A in which glucose, the sole carbon source, was reduced from 10 to $3 \mathrm{~g}^{-1}$, and EMM2A(G-0) - EMM2A from which the glucose was omitted. When required, $1 \%(\mathrm{w} / \mathrm{v})$ agar (no. 1, Oxoid) was added to EMM2A or one of its variants.

Strains. The strains used are listed, in cluster order, in Table 1. Strains were checked for purity on receipt and maintained on slopes of MEA at $4^{\circ} \mathrm{C}$.

Growth conditions. All cultures were incubated aerobically at $30^{\circ} \mathrm{C}$ without shaking unless otherwise stated.

Preparation of inocula. Each strain to be tested was grown in PYGM for $1 \mathrm{~d}$. After harvesting by centrifugation, cells were washed once with and then resuspended in EMM2A(G-0) to give an absorbance reading of $0 \cdot 1$ at a wavelength of $550 \mathrm{~nm}$ in a spectrophotometer (Spectronic 20, Bausch \& Lomb).

† Present address: Commonwealth Mycological Institute, Kew, Surrey TW9 3AF, UK. 
Table 1. Strains arranged in cluster order $\left(S_{S M}\right.$ coefficient $)$

\begin{tabular}{|c|c|}
\hline $\begin{array}{l}\text { Monash } \\
\text { designation }\end{array}$ & Name as received \\
\hline MY1 & Schizosaccharomyces pombe Lindner \\
\hline MY2 & S. pombe Lindner \\
\hline MY27 & $\begin{array}{l}\text { S. pombe Lindner } \\
\text { (syn. S. asporus Beijerinck) }\end{array}$ \\
\hline MY28 & $\begin{array}{l}\text { S. pombe Lindner } \\
\text { (syn. S. formosensis Nakazawa } \\
\text { var. tapaniensis Nakazawa) }\end{array}$ \\
\hline MY3 & S. pombe Lindner \\
\hline MY35 & $\begin{array}{l}\text { S. pombe Lindner } \\
\text { (syn. } S \text {. vordermani Wehmer) }\end{array}$ \\
\hline MY4 & S. pombe Lindner \\
\hline MY18 & $\begin{array}{l}S . \text { pombe Lindner } \\
\text { (syn. S. formosensis Nakazawa } \\
\text { var. akoensis Nakazawa) }\end{array}$ \\
\hline MY6 & S. pombe Lindner \\
\hline $\begin{array}{l}\text { MY15 } \\
\text { MY8 }\end{array}$ & $\begin{array}{l}\text { S. pombe Lindner } \\
\text { S. malidevorans Rankine \& Fornachon }\end{array}$ \\
\hline
\end{tabular}

MY16 S. pombe Lindner

(syn. S. liquefaciens Osterwalder)

MY19 S. pombe Lindner

MY9 Schizosaccharomyces sp.

MY10 Schizosaccharomyces sp.

MY11 Schizosaccharomyces sp.

MY12 Schizosaccharomyces sp.

MY17 S. pombe Lindner

(syn. S. formosensis Nakazawa)

MY42 S. mosquensis Shcerbakov \& Popova

MY47 S. pombe Lindner

MY48 S. malidevorans Rankine \& Fornachon

MY29 S. pombe Lindner

(syn. S. pinan Nakazawa)

MY33 S. pombe Lindner

(syn. S. santawensis Nakazawa)

MY41 S. mellacei Jorgensen

MY30 S. pombe Lindner

(syn. S. pombe Lindner var.

ogasawaraensis Sakaguchi \& Ohtani)

MY31 S pombe Lindner

(syn. S. pombe Lindner var. iotoensis Sakaguchi \& Ohtani)

MY32 S. pombe Lindner (syn. S. liquefaciens Osterwalder)

MY43 S. acidodevoratus Tschalenko

MY34 S. pombe Lindner (syn. S. taito Nakazawa)

MY44 S. pombe Lindner

MY46 S. pombe Lindner

MY56 S. pombe Lindner

MY57 S. pombe Lindner

MY58 S. pombe Lindner

MY55 S. pombe Lindner

MY51 S. pombe Lindner

MY52 S. pombe Lindner

MY53 S. pombe Lindner (syn. S. liquefaciens Osterwalder)
Source* and

designation

Comments*

$\begin{array}{ll}\text { AWRI 160 } & \text { Vineyard } \\ \text { AWRI 161A } & \text { UCD 227 } \\ \text { IFO 0340 } & \end{array}$

IFO 0344

CBS 1062, NRRL Y-1358; cane-sugar molasses

AWRI 161

IFO 0366

L972

CBS 1044

CBS 356

AWRI 158

CBS 1042

CBS 1059

RYCC 24/5

RYCC 24/6

RYCC 24/7

RYCC 24/4

CBS 1043

RIVE 4-2-1

CBS 5682

CBS 5557

IFO 0345

IFO 0364

RIVE 4-5-1

IFO 0347

Obtained via JMM;

ATCC 24969, NCYC 1354

IFO 0343; cane-sugar

molasses

Variant of MY5

(Mahadi, 1977)

Type strain; UCD C277

Type strain; CBS 5557,

IFO 1608, NCYC 683 ,

RIVE 4-6-1, UCD 70-49;

Listan grapes

ATCC 16979, IFO 0358;

grape juice

Cane sugar

Sulphited grape juice

Sulphited grape juice

Sulphited grape juice

Sulphited grape juice

IFO 0342; cane-sugar

molasses

Bantu beer

Type strain; AWRI 158, IFO 1608, NCYC 683, RIVE 4-6-1; UCD 70-49; Listan grapes

CBS 355, NRRL Y-1359; molasses

CBS 1063, NRRL Y-1362; cane-sugar molasses

CBS 2775

IFO 0349

CBS 2776

IFO 0358

RIVE 4-1-1

IFO 0365

ATCC 16979, CBS 1042; grape juice

CBS 357

CBS 2777

NCYC 132

NCYC 936

NCYC 380

CBS 1058

IFO 0346

IFO 0351

IFO 0638
CBS 1061, NRRL Y-1605; cane-sugar molasses

Cane-sugar molasses IFO 0348

ATCC 24751 ; millet beer

Fermenting toddy

Cane sugar

Molasses 
Table 1 (continued)

\begin{tabular}{|c|c|}
\hline $\begin{array}{c}\text { Monash } \\
\text { designation }\end{array}$ & Name as received \\
\hline MY5 & S. pombe Lindner \\
\hline $\begin{array}{l}\text { MY45 } \\
\text { MY54 } \\
\text { MY13 }\end{array}$ & $\begin{array}{l}\text { S. pombe Lindner } \\
\text { S. pombe Lindner } \\
\text { S. japonicus Yukawa \& Maki } \\
\text { var. japonicus }\end{array}$ \\
\hline MY14 & $\begin{array}{l}\text { S. japonicus Yukawa \& Maki } \\
\text { var. versatilis (Wickerham \& Duprat) Slooff }\end{array}$ \\
\hline MY21 & $\begin{array}{l}\text { S. japonicus Yukawa \& Maki } \\
\text { var. versatilis (Wickerham \& Duprat) Slooff }\end{array}$ \\
\hline MY36 & $\begin{array}{l}\text { S. japonicus Yukawa \& Maki } \\
\text { var. japonicus }\end{array}$ \\
\hline MY38 & $\begin{array}{l}\text { S. japonicus Yukawa \& Maki } \\
\text { var. japonicus }\end{array}$ \\
\hline MY61 & $\begin{array}{l}\text { S. japonicus Yukawa \& Maki } \\
\text { var. versatilis (Wickerham \& Duprat) Slooff }\end{array}$ \\
\hline MY20 & $\begin{array}{l}\text { S. japonicus Yukawa \& Maki } \\
\text { var. versatilis (Wickerham \& Duprat) Slooff }\end{array}$ \\
\hline MY37 & $\begin{array}{l}\text { S. japonicus Yukawa \& Maki } \\
\text { var. japonicus }\end{array}$ \\
\hline MY7 & S. octosporus Beijerinck \\
\hline MY25 & S. octosporus Beijerinck \\
\hline MY23 & S. octosporus Beijerinck \\
\hline MY24 & S. octosporus Beijerinck \\
\hline MY26 & S. slooffiae Kumbhojkar \\
\hline MY39 & S. octosporus Beijerinck \\
\hline MY40 & S. octosporus Beijerinck \\
\hline MY60 & S. octosporus Beijerinck \\
\hline MY50 & S. octosporus Beijerinck \\
\hline MY59 & S. octosporus Beijerinck \\
\hline MY49 & S. octosporus Beijerinck \\
\hline
\end{tabular}

Source* and designation

NCYC 132

CBS 2628

CBS 1057

AWRI 156

AWRI 157

CBS 5679

IFO 1646

IFO 1713

NCYC 419

CBS 2629

IFO 1712

AWRI 159

CBS 6209

CBS 2632

CBS 6206

CBS 6207

IFO 0353

IFO 0360

NCYC 427

NRRL Y-854

NCYC 131

CBS 371
Comments*

Obtained via JMM; ATCC 24751 ; millet beer

Palm wine

From brewer's yeast

Type strain: ATCC 10660, CBS 354, IFO 1609, NRRL Y-1361, UCD 71-26; strawberry wine

Type strain; ATCC 9987, CBS 103, IFO 1607, NRRL Y-1026E; homecanned grape juice ATCC 24256, UCD 60-255; slime flux of Ulmus carpinifolia

Slime flux of tree

* Abbreviations: ATCC, American Type Culture Collection, Rockville, Md., USA; AWRI, Australian Wine Research Institute, Adelaide, South Australia; CBS, Centraalbureau voor Schimmelcultures (Yeast Division), Delft, The Netherlands; IFO, Institute for Fermentation, Osaka, Japan; JMM, Professor J. M. Mitchison, Department of Zoology, University of Edinburgh, Edinburgh, Scotland; L, Professor U. Leupold, Institute of General Microbiology, University of Bern, Switzerland; NCYC, National Collection of Yeast Cultures, Food Research Institute, Norwich, England; NRRL, Northern Regional Research Center, US Department of Agriculture, Peoria, Illinois, USA; RIVE, Research Institute for Viticulture and Enology, Bratislava, Czechoslovakia; RYCC, Roseworthy Yeast Culture Collection, Roseworthy Agricultural College, Roseworthy, South Australia; UCD, Department of Food Science and Technology, University of California, Davis, California, USA.

Inoculation of test media. Liquid media were inoculated with $0.1 \mathrm{ml}$ of washed cell suspension. Except for plates of MEA required for the study of colonial appearance and sporulation, plates of agar media were inoculated with a matrix of 25 strains using a multipoint inoculator (May \& Houghton, 1965).

Colonial and cellular morphology. Colonial appearance and number of spores per ascus were ascertained after 7 d on MEA. Colonial morphology was described using criteria given by Wilson \& Miles (1964) and Lodder (1970). Length and width of cells just prior to division (i.e. showing a cell plate) were ascertained after $2 \mathrm{~d}$ in PYGM. Formation of hyphae penetrating the agar surrounding an area of growth was ascertained after $7 \mathrm{~d}$ on MEA incubated anaerobically (Gas Pak Anaerobic System, BBL).

Growth at different temperatures. Ability to grow at $4{ }^{\circ} \mathrm{C}(14 \mathrm{~d}), 10^{\circ} \mathrm{C}(14 \mathrm{~d}), 37^{\circ} \mathrm{C}(7 \mathrm{~d}), 40^{\circ} \mathrm{C}(5 \mathrm{~d})$ and $45^{\circ} \mathrm{C}$ (5 d) was tested in PYGM. 
Growth at $\mathrm{pH} 3 \cdot 3$. Ability to grow within $10 \mathrm{~d}$ was tested on MEA adjusted to $\mathrm{pH} 3 \cdot 3$.

Growth with various inhibitors. Ability to grow within $10 \mathrm{~d}$ was tested on EMM2A agar containing in turn each of the substances listed in Tabie 3 (nos 28-66 inclusive) at the stated concentrations.

Ability to grow within $10 \mathrm{~d}$ was also tested on Bismuth Sulphite Agar (Oxoid) adjusted to pH 5.6.

Assimilation of carbohydrates. Ability to grow within $14 \mathrm{~d}$ was tested on EMM2A(G-0) agar containing in turn each of the following filter-sterilized carbohydrates $\left(10 \mathrm{~g}^{-1}\right)$ : dihydroxyacetone, D-fructose, D-galactose, $\alpha-\mathrm{D}$ glucosamine, D-glucose, glycerol. maltose, D-mannose, raffinose, D-ribose, L-sorbose, sucrose, trehalose and xylose.

Fermentation of carbohydrates. Ability to produce gas from carbohydrates within $28 \mathrm{~d}$ was tested in EMM2A(G-0) containing in turn each of the following carbohydrates $\left(10 \mathrm{~g}^{-1}\right)$ : D-fructose, D-galactose, Dglucose, glycerol, maltose, D-mannose, raffinose and sucrose. Gas formation was detected using a Durham tube in each bottle of medium.

Production of proteases. Digestion of casein was tested after $10 \mathrm{~d}$ on EMM2A(G-3) agar containing $30 \%(w / v)$ Skimmed Milk Medium (Difco). A clear zone around an area of growth after flooding with $10 \%(\mathrm{w} / \mathrm{v})$ solution of $\mathrm{HgCl}_{2}$ was scored as positive.

Liquefaction of gelatin was tested after $10 \mathrm{~d}$ in EMM2A containing $12 \%(w / v)$ gelatin. Failure of the medium to reform a gel after chilling was scored as positive.

Enzymic activities. Aesculin hydrolysis was ascertained after $10 \mathrm{~d}$ on EMM2A(G-3) agar containing $1 \%(\mathrm{w} / \mathrm{v})$ aesculin and $0.05 \%(\mathrm{w} / \mathrm{v})$ ferric chloride. Blackening of the medium around an area of growth was scored as positive.

Catalase activity was tested after $10 \mathrm{~d}$ on MEA. Effervescence after application of $3 \%(\mathrm{v} / \mathrm{v})$ hydrogen peroxide was scored as positive.

DNAase activity was tested after $10 \mathrm{~d}$ on EMM2A agar containing $0 \cdot 2 \%$ (w/v) DNA (sodium salt, BDH). A clear zone around an area of growth after flooding with $1 \mathrm{M}-\mathrm{HCl}$ was scored as positive.

Phosphatase activity was tested after $10 \mathrm{~d}$ on EMM2A agar containing $0.01 \%(\mathrm{w} / \mathrm{v})$ phenolphthalein diphosphate. Pink coloration of growth after exposure to vapour from ammonia solution (sp. gr. 0.88) was scored as positive.

Starch hydrolysis was tested after $10 \mathrm{~d}$ on EMM2A(G-3) agar containing $1 \%(w / v)$ soluble starch. A clear zone around an area of growth was scored as positive.

Urease activity was ascertained after $5 \mathrm{~d}$ on slopes of EMM2A agar containing $2 \%(w / v)$ filter-sterilized urea as the sole nitrogen source and $0.12 \%(\mathrm{w} / \mathrm{v})$ phenol red. A reddening of the medium was scored as positive.

Metabolic end products. Production of acetoin after $10 \mathrm{~d}$ in PYGM was tested using method 1 described by Cowan (1974).

Hydrogen sulphide production was ascertained after $10 \mathrm{~d}$ in PYGM containing sodium thiosulphate $\left(0.005 \mathrm{~g}^{-1}\right)$. Blackening of a lead acetate impregnated paper (Cowan, 1974) fixed above the medium was scored as positive.

Reduction of tellurite. Blackening of growth after $10 \mathrm{~d}$ on EMM2A agar containing potassium tellurite $\left(0.032 \mathrm{~g} \mathrm{l}^{-1}\right)$ was scored as positive.

Numerical methods. Reproducibility was estimated within this study by two methods. Firstly, duplicate cultures of five strains (MY1, MY12, MY23, MY31 and MY48) were maintained and tested independently, the duplicate cultures being indicated in the phenogram (Fig. 1) by the suffix A. Secondly, ten tests (nos 24, 25, 37, 57, 58, 62, 70, 73,75 and 76) were duplicated for all strains. Test error was estimated using formula 1 of Sneath \& Johnson (1972). Vigour values were calculated as the proportion of positive results for each strain.

A data matrix was constructed for the 60 strains and 5 duplicate cultures. Characters that gave either all positive or all negative results were deleted from the computations. The final data matrix contained information from 80 unit characters.

A computer program based upon methods of $\mathbf{M}$. J. Sackin and associates (Leicester University) was used to construct similarity matrices using both the simple matching coefficient $\left(S_{S M}\right)$ and the pattern difference $\left(D_{P}\right)$. Phenograms were constructed using average linkage (UPGMA) methods as given by Sneath \& Sokal (1973). Cophenetic discrepancies, that is the lack of correlation between respective similarity values in a matrix and its corresponding phenogram, were assessed using the correlation coefficient ( $r$; see Sneath, 1978). The inter-centroid taxonomic distance between two clusters $\mathrm{J}$ and $\mathrm{K}\left(d_{J K}\right)$ and the mean taxonomic distance of strains of a cluster to their own centroid $\left(a_{j}\right)$ were calculated using formulae given by Sneath \& Sokal (1973) and Bridge \& Sneath (1983).

The computer program OVCLUST (Sneath, 1979) was used to calculate the overlap statistics for each pair of clusters in Euclidean space. An index of overlap $\left(V_{G}\right)$, which is based upon the number of strains in each of the two clusters, the inter-centroid distance and the distances of strains to the centroids, was calculated and compared to a critical level of overlap $\left(V_{\text {crit }}\right)$ by a non-central $t$-test. A value of $1 \%$ was used as the critical level of overlap when comparing each pair of clusters. Since the program OVCLUST allows for a correction to be made for sampling error based on the number of tests, computations were made both with and without this correction.

A Digital Equipment Corporation VAX 11 computer was used for all data processing. 


\section{RESULTS AND DISCUSSION}

\section{Cluster analysis}

Both the $S_{S M}$ and the $D_{P}$ produced three major clusters, the composition and structure of which were essentially the same with each coefficient. The phenogram derived using the $S_{S M}$ is shown in Fig. 1, the parameters of the three resulting clusters are listed in Table 2 and the characteristics of each cluster are listed in Table 3. A list of the most differential tests for the clusters observed is given in Table 4.

Although differences in vigour may cause more distortion of the clustering obtained with $S_{S M}$ than with $D_{P}$ (Sneath, 1968; Sneath \& Sokal, 1973), the good agreement between the clustering obtained with the two coefficients implies that the observed differences in vigour (Table 2) did not have a significant effect. In addition, the correlation coefficient $(r)$ between a similarity matrix and its corresponding phenogram was 0.9404 for the $S_{S M}$ and 0.880 for the $D_{P}$, these values being quite acceptable for a study employing UPGMA. The classification described below is based upon the phenogram derived with the $S_{S M}$ and results using $D_{P}$ are referred to in the text only where they showed any apparent differences.

\section{Description and identity of clusters}

Cluster 1 was named Schizosaccharomyces pombe. This cluster contained 41 strains of which 4 were duplicated. These 41 strains consisted of all 32 strains, including the type strain (MY15), of $S$. pombe, 3 strains (MY41, MY42 and MY43) received as $S$. mellacei, $S$. mosquensis and $S$. acidodevoratus respectively, 2 strains (MY8 and MY48) received as the type strain of $S$. malidevorans, and 4 strains (MY9, MY10, MY11 and MY12) received as species of Schizosaccharomyces.

Using the $S_{S M}$, six strains (MY51, MY52, MY53, MY5, MY45 and MY54) were loosely linked at the base of cluster 1, although using $D_{P}$ only two strains occupied this position. Since all six strains were incorporated at an $S_{S M}$ of at least $83 \%$ and because of the large difference in similarity between this cluster and its nearest neighbour (cluster 2), these strains were considered to be part of cluster 1 .

The characteristics of cluster 1 (see Table 3 ) were in general agreement with the findings of Slooff (1970) for $S$. pombe, although there were three notable exceptions. Whereas Slooff (1970) reported that members of this species fermented raffinose and failed to or only weakly assimilated glycerol, and that certain strains liquefied gelatin, we found that $91 \%$ of strains failed to ferment raffinose, $93 \%$ of strains assimilated glycerol, and three strains (MY16, MY32 and MY53) previously designated $S$. liquefaciens, failed to liquefy gelatin. The concentration (approximately $17 \mathrm{~mm}$ ) of raffinose used in this study may have been insufficient to allow visible gas formation given the size of the inoculum and the incubation period, particularly since other workers have used concentrations of $50 \mathrm{mM}$ (Barnett et al., 1979), $68 \mathrm{mM}$ (Lodder, 1970) and $200 \mathrm{~mm}$ (Beech et al., 1968). Unfortunately it was not possible to retest the strains described here at higher concentrations of carbohydrate. The higher proportion of strains assimilating glycerol was not surprising since the enzymes involved in glycerol utilization by $S$. pombe were described recently (May \& Sloan, 1981; May et al., 1982) and were present in all members of cluster 1 (G. Vasiliadis, personal communication). The failure of strains formerly designated $S$. liquefaciens to liquefy gelatin may reflect either loss of the property during maintenance or lack of expression due to the composition of the medium and/or the cultural conditions employed.

The two lines of the type strain of $S$. malidevorans were well separated in cluster $1\left(S_{S M}=\right.$ $\left.87 \%, D_{P}=0.13\right)$. Line MY8, obtained from the Australian Wine Research Institute, showed properties similar to those described by Rankine \& Fornachon (1964): it grew well at $37^{\circ} \mathrm{C}$, assimilated maltose and was homothallic. Line MY48, obtained from the Centraalbureau voor Schimmelcultures, showed properties closer to those described by Sipiczki et al. (1982): it grew poorly at $37^{\circ} \mathrm{C}$, failed to assimilate maltose and was heterothallic. Like the line used by Sipiczki et al. (1982), line MY48 probably originated from a stable mating-type mutant (see Leupold, 1970 ) and this may have been responsible for the physiological differences between MY8 and MY48. 


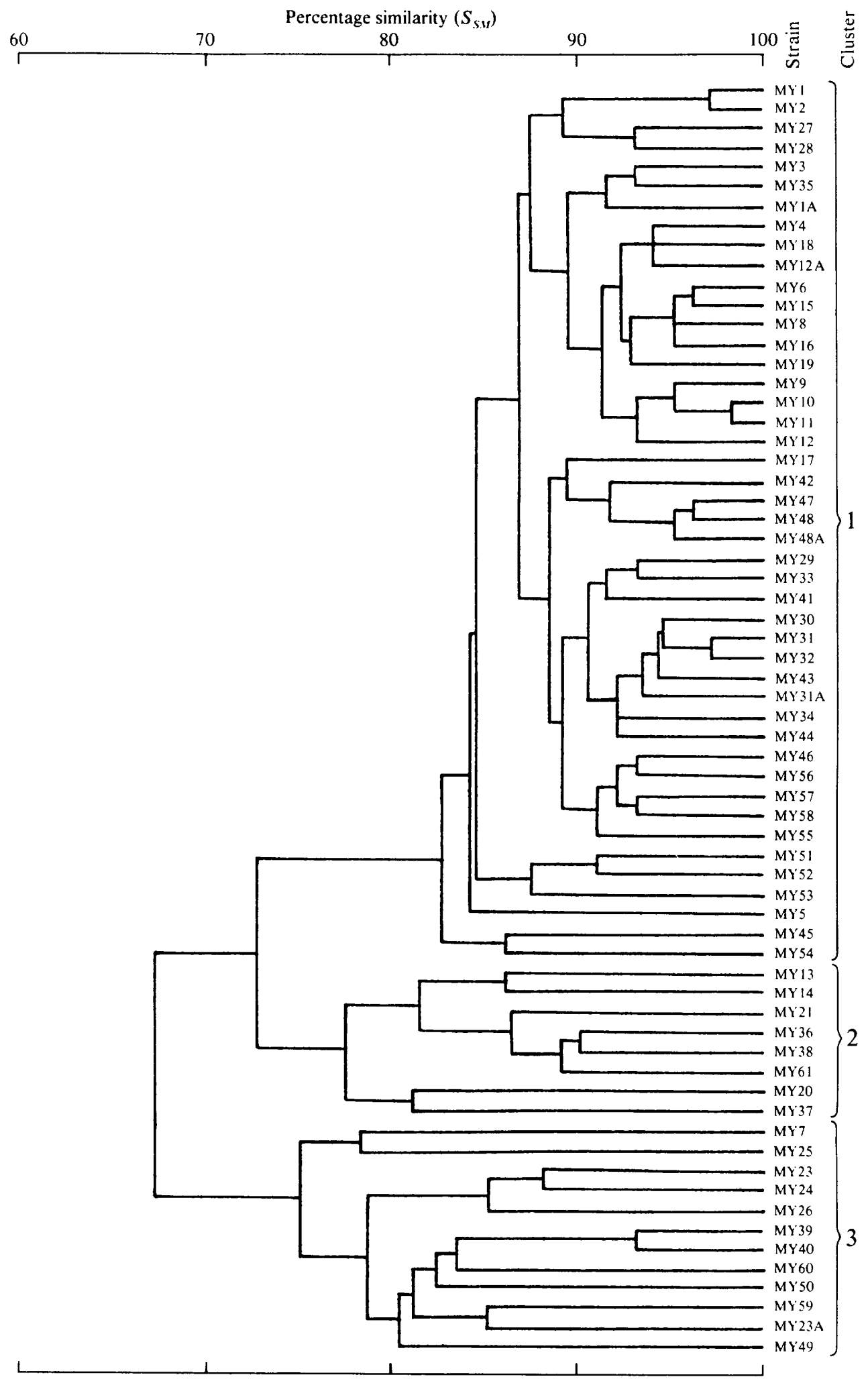

Fig. 1. UPGMA phenogram based on $S_{S M}$. 
Table 2. Parameters of clusters

The mean vigour for a cluster is the average of all of the individual strain vigour values in the cluster, with SD indicating the standard deviation of these values; $\vec{d}_{J}$ is the mean taxonomic distance of strains of a cluster to their own centroid; and $d_{J K}$ is the inter-centroid taxonomic distance between clusters $J$ and $K$.

\begin{tabular}{|c|c|c|c|}
\hline & Cluster 1 & Cluster 2 & Cluster 3 \\
\hline No. of strains & 45 & 8 & 12 \\
\hline Mean vigour & 0.483 & 0.371 & 0.390 \\
\hline SD & 0.028 & 0.052 & 0.039 \\
\hline$\vec{d}_{j}$ & 0.252 & 0.306 & 0.324 \\
\hline Cluster 1 & 0.0 & . & . \\
\hline$d_{J K}\{$ cluster 2 & 0.361 & 0.0 & . \\
\hline [cluster 3 & 0.417 & 0.361 & 0.0 \\
\hline
\end{tabular}

The inclusion of $S$. malidevorans within cluster 1 was expected since this species and $S$. pombe were similar in the chemotaxonomic studies of Yamada et al. (1973), Stewart \& Widanapatirana (1974) and Claisse \& Simon-Becam (1978). Recently, Sipiczki et al. (1982) proposed $S$. malidevorans as a variety of $S$. pombe on the basis of results from interfertility studies. Our results suggest that there is insufficient distinction between the two to justify variety status for $S$. malidevorans and that it should be a member of the species $S$. pombe. We found no basis for separation of subgroups or biotypes within the clusters (see below: Overlap); this is consistent with the decision of Slooff (1970) not to raise to either species or variety level those strains which fermented L-malic acid.

Cluster 2 was named Schizosaccharomyces japonicus. This cluster contained eight strains and consisted of all four strains, including the type strain (MY13), of S. japonicus var. japonicus, and all four strains, including the type strain (MY14), of $S$. japonicus var. versatilis. The constituent strains formed a loose but distinct cluster $\left(S_{S M}=78 \%, D_{P}=0.20\right)$.

The characteristics of the cluster were in broad agreement with those given by Slooff (1970) for $S$. japonicus, although fewer positive results were obtained for assimilation and fermentation of carbohydrates. As suggested previously, this may have been due to the lower concentration of carbohydrates used in this study. The recommended separation of this species into two varieties (Slooff, 1970) was not justified by either $S_{S M}$ or $D_{P}$. Indeed, the inter-varietal pairings in the cluster had a mean $S_{S M}$ equal to $82 \%$ which was higher than that for either of the two groups of intra-varietal pairings in the cluster (mean $S_{S M}=81 \%$ for both). Furthermore, the type strains of $S$. japonicus var. japonicus and $S$. japonicus var. versatilis (MY13 and MY14 respectively) formed a pair at an $S_{S M}$ equal to $86 \%$; and the equal highest similarity in the cluster $\left(S_{S M}=\right.$ $90 \%$ was between MY36 and MY61, strains of $S$. japonicus var. japonicus and $S$. japonicus var. versatilis respectively. Consequently, on the basis of overall similarity, there is no justification for the division of the cluster into sub-clusters corresponding to the varieties japonicus and versatilis.

Cluster 3 was named Schizosaccharomyces octosporus. This cluster contained 11 strains (one of which was duplicated) and consisted of all 10 strains, including the type strain (MY49), of $S$. octosporus and the type strain (MY26) of $S$. slooffiae. The constituent strains were clustered loosely $\left(S_{S M}=75 \%, D_{P}=0.24\right)$, this lack of cohesion being exemplified by MY23 and its duplicate culture MY23A which only joined at an $S_{S M}$ of $79 \%$. Nevertheless, the cluster was sufficiently well separated from its nearest neighbour (cluster 2) to be regarded as distinct.

The characteristics of the cluster were in broad agreement with those given by Slooff (1970) for $S$. octosporus. A notable exception was fermentation of maltose which was reported by Slooff (1970) to be positive, whereas in this study as many as $83 \%$ of the strains in the cluster failed to ferment maltose. Again, this result may have been due to the concentration of carbohydrate used. This inconsistency is inconvenient since inability to ferment maltose was the principal feature distinguishing $S$. slooffiae from $S$. octosporus (Kumbhojkar, 1972); nevertheless, the presence of the type strain of $S$. slooffiae (MY26) near the centre of the cluster indicates that its species status is not justified and that it should be included in $S$. octosporus. 
Table 3. Characteristics of the clusters

1. White colonies

2. Buff colonies

3. Convex colonies

4. Umbonate colonies

5. Conical colonies

6. Entire colonies

7. Crenated colonies

8. Rough colonies

9. Hyphae penetrating agar

10. Colony diameter $<2 \mathrm{~mm}$

11. Colony diameter $2-3 \mathrm{~mm}$

12. Colony diameter $>3 \mathrm{~mm}$

13. Cell length $<8 \mu \mathrm{m}$

14. Cell length $8-10 \mu \mathrm{m}$

15. Cell length $>10 \mu \mathrm{m}$

16. Cell width $<3 \mu \mathrm{m}$

17. Cell width $3-4.5 \mu \mathrm{m}$

18. Cell width $>4.5 \mu \mathrm{m}$

19. Asci containing $<5$ spores

20. Asci containing 5-7 spores

21. Asci containing $>7$ spores

22. Growth at $4^{\circ} \mathrm{C}$

23. Growth at $10^{\circ} \mathrm{C}$

24. Growth at $37^{\circ} \mathrm{C}$

25. Growth at $40^{\circ} \mathrm{C}$

26. Growth at $45^{\circ} \mathrm{C}$

27. Growth at $\mathrm{pH} 3 \cdot 3$

Growth with:

28. Brilliant green $\left(0.01 \mathrm{~g}^{-1}\right)$

29. Caesium chloride $\left(0.005 \mathrm{~g} \mathrm{l}^{-1}\right)$

30. Cobalt nitrate $\left(0.005 \mathrm{~g} \mathrm{I}^{-1}\right)$

31. Cobalt nitrate $\left(0.05 \mathrm{~g}^{-1}\right)$

32. Copper sulphate $\left(0.005 \mathrm{~g}^{-1}\right)$

33. Crystal violet $\left(0.004 \mathrm{~g} \mathrm{l}^{-1}\right)$

34. Crystal violet $\left(0.1 \mathrm{~g}^{-1}\right)$

35. Glucose $\left(500 \mathrm{~g}^{-1}\right)$

36. Glucose $\left(600 \mathrm{~g}^{-1}\right)$

37. Horse blood $\left(50 \mathrm{ml} \mathrm{1}^{-1}\right)$

38. Lead acetate $\left(0.005 \mathrm{~g}^{-1}\right)$

39. Lead acetate $\left(0.05 \mathrm{~g}^{-1}\right)$

40. Lithium chloride $\left(0.005 \mathrm{~g} \mathrm{I}^{-1}\right)$

41. Lithium chloride $\left(0.01 \mathrm{~g}^{-1}\right)$

42. Lysozyme $\left(0.05 \mathrm{~g} \mathrm{l}^{-1}\right)$

43. Lysozyme $\left(0.1 \mathrm{~g} \mathrm{l}^{-1}\right)$

44. Mercuric chloride $\left(0.005 \mathrm{~g}^{-1}\right)$

45. Ox bile $\left(10 \mathrm{~g}^{-1}\right)$

46. Ox bile $\left(100 \mathrm{~g}^{-1}\right)$

47. Potassium tellurite $\left(0.032 \mathrm{~g} \mathrm{I}^{-1}\right)$

48. Potassium tellurite $\left(0.32 \mathrm{~g}^{-1}\right)$

49. Rose bengal $\left(0.05 \mathrm{~g}^{-1}\right)$

50. Rose bengal $\left(0.5 \mathrm{~g}^{-1}\right)$

Percentage of strains positive

\begin{tabular}{rcc}
\hline Cluster 1 & Cluster 2 & Cluster 3 \\
100 & 63 & 8 \\
0 & 37 & 92 \\
73 & 63 & 8 \\
0 & 37 & 42 \\
27 & 0 & 50 \\
100 & 100 & 33 \\
0 & 0 & 67 \\
0 & 13 & 92 \\
0 & 100 & 0 \\
49 & 88 & 42 \\
49 & 12 & 58 \\
2 & 0 & 0 \\
15 & 0 & 17 \\
56 & 25 & 58 \\
29 & 75 & 25 \\
20 & 0 & 0 \\
80 & 0 & 0 \\
0 & 100 & 100 \\
100 & 37 & 8 \\
0 & 63 & 33 \\
0 & 0 & 59 \\
4 & 0 & 0 \\
84 & 75 & 8 \\
96 & 100 & 75 \\
60 & 88 & 25 \\
0 & 0 & 0 \\
100 & 88 & 58 \\
& &
\end{tabular}

$\begin{array}{rrr}0 & 0 & 0 \\ 100 & 75 & 83 \\ 96 & 50 & 25 \\ 2 & 0 & 0 \\ 56 & 13 & 25 \\ 98 & 75 & 83 \\ 20 & 0 & 8 \\ 100 & 0 & 100 \\ 98 & 0 & 100 \\ 84 & 88 & 67 \\ 100 & 100 & 92 \\ 98 & 50 & 67 \\ 98 & 75 & 83 \\ 98 & 62 & 67 \\ 98 & 88 & 75 \\ 98 & 75 & 67 \\ 0 & 0 & 0 \\ 100 & 100 & 100 \\ 27 & 25 & 67 \\ 100 & 100 & 92 \\ 0 & 0 & 0 \\ 100 & 13 & 58 \\ 49 & 0 & 0\end{array}$

\section{Test performance and strain variability}

Whereas only $19 \%$ of the tests listed by Barnett et al. (1979) were differential for fission yeasts, $76 \%$ of our set of tests were significantly differential (i.e. between $10 \%$ and $90 \%$ of all strains were positive for a given test). This improvement was almost wholly due to the inclusion of tests for resistance, characteristics seldom used in yeast classification (Lodder, 1979; Barnett et al., 1979), but which are widely used in numerical classification of bacteria (e.g. Goodfellow et al., 
Table 3 (continued)

\section{Character}

51. Silver nitrate $\left(0.005 \mathrm{~g}^{-1}\right)$

52. Sodium arsenate $\left(0.02 \mathrm{~g}^{-1}\right)$

53. Sodium arsenate $\left(0.05 \mathrm{~g}^{-1}\right)$

54. Sodium azide $\left(0 \cdot 1 \mathrm{~g}^{-1}\right)$

55. Sodium azide $\left(\mathrm{g}^{-1}\right)$

56. Sodium benzoate $\left(1 \mathrm{~g}^{-1}\right)$

57. Sodium benzoate $\left(10 \mathrm{~g}^{-1}\right)$

58. Sodium chloride $\left(30 \mathrm{~g}^{-1}\right)$

59. Sodium chloride $\left(40 \mathrm{~g}^{-1}\right)$

60. Sodium chloride $\left(60 \mathrm{~g}^{-1}\right)$

61. Sodium chloride $\left(100 \mathrm{~g}^{-1}\right)$

62. Sodium chloride $\left(150 \mathrm{~g} \mathrm{l}^{-1}\right)$

63. Sodium dodecyl sulphate $\left(\mathrm{g}^{-1}\right)$

64. Sodium hydrogen selenite $\left(0.032 \mathrm{~g}^{-1}\right)$

65. Tetrazolium salt $\left(0.032 \mathrm{~g}^{-1}\right)$

66. Zinc acetate $\left(0.005 \mathrm{~g} \mathrm{l}^{-1}\right)$

67. Growth on Bismuth Sulphite Agar (pH 5.6)

Assimilation of carbohydrates $\left(10 \mathrm{gl}^{-1}\right)$ :

68. Dihydroxyacetone

69. D-Fructose

70. D-Galactose

71. $\alpha-D-G$ lucosamine

72. D-Glucose

73. Glycerol

74. Maltose

75. D-Mannose

76. Raffinose

77. D-Ribose

78. L-Sorbose

79. Sucrose

80. Trehalose

81. Xylose

Fermentation of carbohydrates $\left(10 \mathrm{~g}^{-1}\right)$ :

82. D-Fructose

83. D-Galactose

84. D-Glucose

85. Glycerol

86. Maltose

87. D-Mannose

88. Raffinose

89. Sucrose

90. Casein digestion

91. Gelatin liquefaction

92. Aesculin hydrolysis

93. Catalase

94. DNAase

95. Phosphatase (pH 5.6)

96. Starch hydrolysis

97. Urease

98. Acetoin production

99. $\mathrm{H}_{2} \mathrm{~S}$ production

100. Reduction of potassium tellurite

Percentage of strains positive

$\overbrace{\text { Cluster } 1 \quad \text { Cluster } 2 \quad \text { Cluster } 3}$

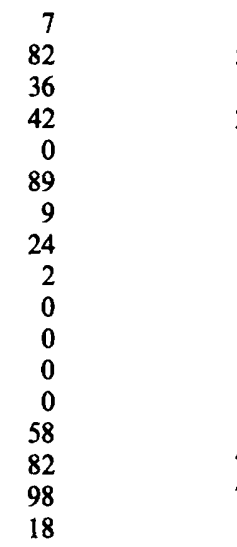

$0 \quad 0$

$50 \quad 50$

$13 \quad 25$

$25 \quad 0$

0

$13-0$

$0 \quad 0$

$13 \quad 92$

$0 \quad 92$

$0 \quad 75$

$0 \quad 42$

$0 \quad 17$

0

$0-8$

$75-83$

$75-75$

0

$80 \quad 0 \quad 0$

$\begin{array}{lll}100 & 88 & 83\end{array}$

$\begin{array}{lll}0 & 0 & 0 \\ 0 & 0 & 0\end{array}$

$100 \quad 100 \quad 100$

$93 \quad 000$

$96 \quad 100 \quad 100$

$89 \quad 50 \quad 67$

$\begin{array}{lll}96 & 25 & 8\end{array}$

$\begin{array}{lll}0 & 0 & 0 \\ 0 & 0 & 0\end{array}$

$100 \quad 100 \quad 83$

$\begin{array}{lll}0 & 0 & 0 \\ 0 & 0 & 0\end{array}$

$96 \quad 75 \quad 75$

$\begin{array}{rrr}0 & 0 & 0 \\ 100 & 100 & 100\end{array}$

0000

$\begin{array}{lll}93 & 100 & 17\end{array}$

$82 \quad 63 \quad 50$

950

$\begin{array}{lll}100 & 38 & 17\end{array}$

$\begin{array}{lrl}0 & 13 & 0 \\ 0 & 0 & 0\end{array}$

$\begin{array}{rrr}0 & 0 & 0 \\ 0 & 50 & 0\end{array}$

$100 \quad 100 \quad 100$

$\begin{array}{rrr}0 & 0 & 0 \\ 96 & 100 & 58\end{array}$

000

$96 \quad 75 \quad 92$

4000

$\begin{array}{lll}47 & 50 & 92\end{array}$

$\begin{array}{lll}100 & 63 & 75\end{array}$

1976; Piot et al., 1980; Schofield \& Schaal, 1981; Bridge \& Sneath, 1983; Williams, et al., 1983).

Results from the duplicated tests showed differences between $1.6 \%$ and $13.1 \%$, the mean difference being $8.5 \%(\mathrm{SE}= \pm 0.92)$. This is within the range regarded as acceptable in a study of this kind (Sneath \& Johnson, 1972).

In bacterial taxonomy characters derived from morphological features have often been shown 
Table 4. Plus-minus table of the most differential characters for all three clusters

Character

1. White colonies

2. Buff colonies

9. Hyphae penetrating agar

17. Cell width $3-4.5 \mu \mathrm{m}$

18. Cell width $>4.5 \mu \mathrm{m}$

19. Asci containing $<5$ spores

23. Growth at $10^{\circ} \mathrm{C}$

35 . Growth with glucose $\left(500 \mathrm{~g} \mathrm{t}^{-1}\right)$

36. Growth with glucose $\left(600 \mathrm{~g} \mathrm{l}^{-1}\right)$

49. Growth with rose bengal $\left(0.05 \mathrm{~g} \mathrm{I}^{-1}\right)$

56. Growth with sodium benzoate $\left(\mathrm{g}^{-1}\right)$

58. Growth with sodium chloride $\left(30 \mathrm{~g}^{-1}\right)$

59. Growth with sodium chloride $\left(40 \mathrm{~g} \mathrm{l}^{-1}\right)$

68. Assimilation of dihydroxyacetone

73. Assimilation of glycerol

76. Assimilation of raffinose

86. Fermentation of maltose

89. Fermentation of sucrose
Cluster 1

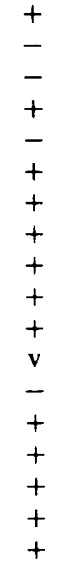

Cluster 2

Cluster 3

,$- \leqslant 20 \%$ of strains positive; $v, 21-79 \%$ of strains positive;,$+ \geqslant 80 \%$ of strains positive.

to be poorly reproducible (Sneath \& Collins, 1974). Yeast taxonomy is governed by the articles of the International Code of Botanical Nomenclature (Stafleu, 1978) and so morphological features must be considered. In this study, the use of standard morphological descriptions and the distinctive features of the organisms enabled reproducible results to be obtained.

Results from the duplicated cultures included in the numerical analysis showed a mean $S_{S M}$ of $89 \cdot 1 \%(\mathrm{SE}= \pm 2 \cdot 6)$ when compared with their parent cultures. Four of the five pairs showed $S_{S M}$ values equal to or greater than 87\%, whereas for the fifth pair (MY23 and MY23A) the value was only $79 \%$. Nevertheless, the mean corresponds to a test error of $5.9 \%$, which is considered acceptable (Sneath \& Johnson, 1972).

We have also observed $S_{S M}$ values as low as $87 \%$ between different lines of the same strain in two cases in addition to that of $S$. malidevorans. The first case involves MY5, MY6 and MY56 which are different lines of $S$. pombe NCYC 132. This strain appears to be inherently unstable: Mitchison \& Creanor (1971) reported differences in morphology and timing of DNA synthesis for two separate lines and Mahadi (1977) observed that, in contrast to MY5, MY6 was unable to assimilate glycerol and produced less acid phosphatase following derepression. The second case involves MY16 and MY32 which are different lines of a strain of S. liquefaciens (CBS 1042 and IFO 0358 respectively) maintained separately since 1946. These two lines showed consistent differences in six tests, including cell size, ability to assimilate mannose and ability to grow in the presence of sodium chloride $\left(30 \mathrm{~g}^{-1}\right)$. Similar persistent variations in yeast cultures were observed by Stahl \& Esser (1979) who concluded that accumulation of mutants during prolonged subculturing was responsible. Such variations may have significant implications for existing yeast taxonomies, particularly those in which disproportionate weight is given to a particular character (Beech et al., 1968; Griffiths, 1981 ; Payne et al., 1982).

\section{Overlap}

For each pair of clusters, a $t$-test showed that overlap was significantly less than $1 \%$ at a confidence level of $99 \%$. Varying the number of test results used for correction of sampling error, as described by Bridge \& Sneath (1983), showed no significant alteration in the confidence level. The same procedure was used to show that no apparent subclusters were sufficiently distinct to justify subdivision of any cluster.

\section{General taxonomic considerations and conclusions}

Reproduction by binary fission sets members of the genus Schizosaccharomyces apart from all other ascosporogenous yeasts (Lodder, 1970). However, this character was not considered 
directly in this study nor were representatives of other genera of yeasts included. Given these restraints, it was not possible to consider the position of Schizosaccharomyces within the overall context of yeast classification.

The proposal of Kudriavzev (see Slooff, 1970) to divide fission yeasts into two genera, Schizosaccharomyces (consisting of the four-spored $S$. pombe and $S$. malidevorans) and Octosporomyces (consisting of the eight-spored $S$. japonicus and $S$. octosporus), was supported by the finding of coenzyme $\mathrm{Q}_{10}$ in $S$. pombe and $S$. malidoevorans and of coenzyme $\mathrm{Q}_{9}$ in $S$. japonicus and $S$. octosporus (Yamada et al., 1973). Although our results revealed the distinctness of $S$. pombe and $S$. malidevorans (cluster 1 ) from $S$. japonicus (cluster 2) and $S$. octosporus (cluster 3 ), in view of the reported low similarity values between yeast taxa generally accepted as species within the same genus (Campbell, 1973, 1974), further studies are required to establish the precise taxonomic status of the clusters.

The results of this study show that the genus Schizosaccharomyces Lindner consists of three distinct taxa corresponding to the species $S$. pombe Lindner, $S$. japonicus Yukawa \& Maki and $S$. octosporus Beijerinck as described by Slooff (1970). Although each species showed some loosely linked members, there was no evidence for the subdivision of any species into varieties.

We wish to thank Dr E. Minarik (Research Institute for Viticulture and Enology, Bratislava), Professor J. M. Mitchison (Department of Zoology, University of Edinburgh), Dr P. Monk (Australian Wine Research Institute, South Australia) and Dr A. S. J. Yap (Roseworthy Agricultural College, South Australia) for the gift of strains held in their collections.

\section{REFERENCES}

Barnett, J. A., Payne, R. W. \& Yarrow, D. (1979). A Guide to Identifying and Classifying Yeasts. Cambridge University Press.

Beech, F. W., Davenport, R. R., Goswell, R. W. \& BurnetT, J. K. (1968). Two simplified schemes for identifying yeast cultures. In Identification Methods for Microbiologists, vol. 2B, pp. 151-175. Edited by B. M. Gibbs \& D. A. Shapton. London: Academic Press.

Bridge, P. D. \& SNeath, P. H. A. (1983). Numerical taxonomy of Streptococcus. Journal of General Microbiology 129, 565-597.

CAMPBELL, I. (1972). Numerical analysis of the genera Saccharomyces and Kluyveromyces. Journal of General Microbiology 73, 279-301.

CAMPBell, I. (1973). Numerical analysis of Hansenula, Pichia and related yeast genera. Journal of General Microbiology 77, 427-441.

CAMPBELL, I. (1974). Methods of numerical taxonomy for various genera of yeasts. Advances in Applied Microbiology 17, 135-156.

CAMPBell, I. (1975). Numerical analysis and computerized identification of the yeast genera Candida and Torulopsis. Journal of General Microbiology 90, 125132.

Claisse, M. L. \& Simon-Becam, A.-M. (1978). Cytochrome $c$ from Schizosaccharomyces pombe. I. Purification, spectral properties, and amino-acid composition. European Journal of Biochemistry 86, 399-406.

CONTI, S. F. \& NAYLOR, H. B. (1959). Electron microscopy of ultrathin sections of Schizosaccharomyces octosporus. I. Cell division. Journal of Bacteriology 78, 868-877.

Cowan, S. T. (1974). Cowan and Steel's Manual for the Identification of Medical Bacteria, 2nd edn. Cambridge: Cambridge University Press.
Goodfellow, M., Austin, B. \& Dickinson, C. H. (1976). Numerical taxonomy of some yellow-pigmented bacteria isolated from plants. Journal of General Microbiology 97, 219-233.

GRIFFITHS, A. J. (1981). A numericlature of the yeasts. Antonie van Leeuwenhoek 47, 547-563.

Kockova-Kratochvilova, A., Slavikova, E. \& JENSEN, V. (1978). Numerical taxonomy of the yeast genus Debaryomyces Lodder \& Kreger-van $\mathrm{Rij}$. Journal of General Microbiology 104, 257-268.

KUMBHOJKAR, M. S. (1972). Schizosaccharomyces slooffiae Kumbhojkar, a new species of osmophilic yeasts from India. Current Science 41, 151-152.

LEUPOLD, U. (1970). Genetical methods for Schizosaccharomyces pombe. Methods in Cell Physiology 4, 169177.

LODDER, J. (editor) (1970). The Yeasts - a Taxonomic Study, 2nd edn. Amsterdam: North-Holland Publishing Co.

LODDER, J. \& KREger-vaN RiJ, N. J. W. (editors) (1952). The Yeasts - a Taxonomic Study, lst edn. Amsterdam: North-Holland Publishing Co.

MAHADI, N. M. B. (1977). Control of production of sucrase and maltase in Schizosaccharomyces pombe. $\mathrm{PhD}$ thesis, Monash University, Australia.

MAY, J. W. \& Houghton, R. H. (1965). A simple multipoint inoculator. Laboratory Practice 14, 168.

MAY, J. W. \& SLOAN, J. (1981). Glycerol utilization by Schizosaccharomyces pombe: dehydrogenation as the initial step. Journal of General Microbiology 123, 183185.

May, J. W., Marshall, J. H. \& Sloan, J. (1982). Glycerol utilization by Schizosaccharomyces pombe: phosphorylation of dihydroxyacetone by a specific kinase as the second step. Journal of General Microbiology 128, 1763-1766. 
Mrrchison, J. M. (1970). Physiological and cytological methods for Schizosaccharomyces pombe. Methods in Cell Physiology 4, 131-165.

Mrtchison, J. M. \& Creanor, J. (1971). Further measurements of DNA synthesis and enzyme potential during cell cycle of fission yeast Schizosaccharomyces pombe. Experimental Cell Research 69, 244247.

Payne, R. W., Yarrow, D. \& Barnett, J. A. (1982). The construction by computer of a diagnostic key to the genera of yeasts and other such groups of taxa. Journal of General Microbiology 128, 1265-1277.

Piot, P., Van Dyck, E., Goodfellow, M. \& Falkow, S. (1980). A taxonomic study of Gardnerella vaginalis (Haemophilus vaginalis) Gardner and Dukes 1955. Journal of General Microbiology 119, 373-396.

RANKINE, B. C. \& Fornachon, J. C. M. (1964). Schizosaccharomyces malidevorans sp. n., a yeast decomposing L-malic acid. Antonie van Leeuwenhoek 30, 73-75.

SCHofield, G. M. \& SchAAL, K. P. (1981). A numerical taxonomic study of members of the Actinomycetaceae and related taxa. Joumal of General Microbiology 127, 237-259.

SiPICZKI, M., KuCSERA, J., UlasZeWSKi, S. \& ZSOLT, J. (1982). Hybridization studies by crossing and protoplast fusion within the genus Schizosaccharomyces Lindner. Journal of General Microbiology 128, 1989. 2000.

SLOOFF, W. C. (1970). Schizosaccharomyces Lindner. In The Yeasts - a Taxonomic Study', pp. 733-755. Edited by J. Lodder. Amsterdam: North-Holland Publishing $\mathrm{Co}$.

SNEATH, P. H. A. (1968). Vigour and pattern in taxonomy. Journal of General Microbiology 54, 1-11.

Sneath, P. H. A. (1978). Classification of microorganisms. In Essays in Microbiology pp. 9/1-9/31. Edited by J. R. Norris \& M. H. Richmond. Chichester: John Wiley.
SNeath, P. H. A. (1979). BASIC program for a significance test for two clusters in Euclidean space as measured by their overlap. Computers and Geosciences 5, 143-155.

SNEATH, P. H. A. \& Collins, V. G. (1974). A study in test reproducibility between laboratories: report of a Pseudomonas working party. Antonie van Leeuwenhoek 40, 481-527.

SNeath, P. H. A. \& Johnson, R. (1972). The influence on numerical taxonomic similarities of errors in microbiological tests. Journal of General Microbiology 72, 377-392.

SNeath, P. H. A. \& Sokal, R. R. (1973). Numerical Taxonomy. San Francisco: W. H. Freeman.

Stafleu, F. A. (editor) (1978). International Code of Botanical Nomenclature. Utrecht: Bonn, Scheltema \& Holkema.

StaHI, U. \& Esser, K. (1979). Inconsistency in the species concept for yeasts due to mutations during vegetative growth. European Journal of Applied Microbiology and Biotechnology 8, 271-278.

StewarT, D. J. \& WidanapatiRana, S. (1974). 'Finger-print' analysis of cell wall proteins from different yeast species after trypsinization. Microbios 9, 167-172.

Williams, S. T., Goodfellow, M., Alderson, G., Wellington, E. M. H., Sneath, P. H. A. \& SaCkin, M. J. (1983). Numerical classification of Streptomyces and related genera. Journal of General Microbiology 129, 1743-1813.

Wilson, G. S. \& Miles, A. A. (1964). Topley \& Wilson's Principles of Bacteriology and Immunity, vol 1, 5th edn. London: Arnold.

YamadA, Y., ARImoto, M. \& Kondo, K. (1973). Coenzyme $Q$ system in the classification of the ascosporogenous yeast genus Schizosaccharomyces and yeast-like genus Endomyces. Journal of General and Applied Microbiology 19, 353-358. 